Published in final edited form as:

Clin Gastroenterol Hepatol. 2015 April ; 13(4): 731-738.e6. doi:10.1016/j.cgh.2014.07.061.

\title{
A Population-Based Study of Incidence, Risk Factors, Clinical Spectrum, and Outcomes of Ischemic Colitis
}

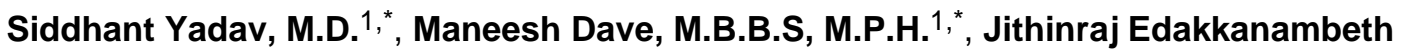 \\ Varayil, M.D. ${ }^{1}$, W. Scott Harmsen, M.S. ${ }^{2}$, William J. Tremaine, M.D. ${ }^{1}$, Alan R. Zinsmeister, \\ Ph.D. ${ }^{2}$, Seth R. Sweetser, M.D. ${ }^{1}$, L. Joseph Melton III, M.D. ${ }^{4}$, William J. Sandborn, M.D. ${ }^{3}$, and \\ Edward V. Loftus Jr., M.D. ${ }^{1}$ \\ ${ }^{1}$ Division of Gastroenterology \& Hepatology, Mayo Clinic, Rochester, Minnesota, USA \\ ${ }^{2}$ Division of Biomedical Statistics \& Informatics, Mayo Clinic, Rochester, Minnesota, USA \\ ${ }^{3}$ Division of Gastroenterology, University of California, San Diego, La Jolla, California, USA \\ ${ }^{4}$ Division of Epidemiology, Mayo Clinic, Rochester, Minnesota, USA
}

\begin{abstract}
Background \& Aims-Little is known about progression of ischemic colitis (IC) among unselected patients. We aimed to estimate the incidence, risk factors, and natural history of IC in a population-based cohort in Olmsted County, Minnesota.

Methods-We performed a retrospective population-based cohort and nested case-control study of IC. Each IC case was matched to 2 controls from the same population based on sex, age, and closest registration number. Conditional logistic regression, the Kaplan-Meier method, and proportional hazards regression were used to assess comorbidities, estimate survival, and identify characteristics associated with survival, respectively.
\end{abstract}

Results-Four hundred forty-five county residents (median age, 71.6 years; 67\% female) were diagnosed with IC from 1976 through 2009 and were matched with 890 controls. The age- and sex-adjusted incidence rates of IC nearly quadrupled, from 6.1 cases/100,000 person-years in

\footnotetext{
(C) 2014 The AGA Institute All rights reserved.

Corresponding Author: Edward V. Loftus, Jr., M.D., Division of Gastroenterology \& Hepatology, Mayo Clinic, 200 First Street, S.W., Rochester, MN 55905, U.S.A., Phone: 1-507-266-0873, Fax: 1-507-284-0538, loftus.edward@ mayo.edu.

*- Co-first authors

Disclosures (last 36 months): This study was supported in part by Mayo Foundation for Medical Education and Research and by a research grant from GlaxoSmithKline. Dr. Loftus has received research support from GlaxoSmithKline. Drs. Yadav, Dave,

Edakkanambeth Varayil, Tremaine, Zinsmeister, Sweetser, Melton, and Sandborn and Mr. Harmsen have no relevant disclosures.

Author Contributions: SY and MD were involved in acquisition and interpretation of data, drafting and critical revision of the manuscript.

JEV was involved in acquisition of data.

WSH and ARZ performed the statistical analysis and critical revision of the manuscript for important intellectual content.

WJT, LJM and SRS were involved in critical revision of the manuscript for important intellectual content. WJS and EVL were involved in study concept, study design, interpretation of data and critical revision of the manuscript for important intellectual content. All authors approved the final version of the manuscript.

Publisher's Disclaimer: This is a PDF file of an unedited manuscript that has been accepted for publication. As a service to our customers we are providing this early version of the manuscript. The manuscript will undergo copyediting, typesetting, and review of the resulting proof before it is published in its final citable form. Please note that during the production process errors may be discovered which could affect the content, and all legal disclaimers that apply to the journal pertain.
} 
1976-1980 to 22.9/100,000 in 2005-2009. The odds for IC were significantly higher among subjects with atherosclerotic diseases; odds ratios ranged from 2.6 for individuals with coronary disease to 7.9 for individuals with peripheral vascular disease. Of IC cases, 59\% survived for 5 years (95\% CI, 54\%-64\%), compared to $90 \%$ of controls (95\% CI, 88\%-92\%). Age >40 years, male sex, right-sided colon involvement, concomitant small bowel involvement, and chronic obstructive pulmonary disease were all independently associated with mortality $(P<.05)$.

Conclusions-The incidence of IC increased over the past 3 decades in a population-based cohort in Minnesota. IC typically presents in older patients with multiple co-morbidities and is associated with high in-hospital mortality (11.5\%) and rates of surgery (17\%).

\section{Keywords}

COPD; epidemiologic study; cardiovascular disease; intestinal vasculature

\section{Introduction}

Ischemic colitis (IC) accounts for approximately $50 \%$ of cases of vascular compromise to the intestine[1]. The condition typically manifests as bloody diarrhea and abdominal pain in elderly individuals who often have a history of atherosclerotic vascular disease, congestive heart failure, recent aortic or cardiopulmonary bypass surgery, or an episode of hypotension[1-3]. However, younger individuals may develop IC in other settings, such as hypercoagulable states, collagen vascular diseases, long-distance running, cigarette smoking, constipation, and use of certain drugs, especially oral contraceptives[4-7]. There is a paucity of epidemiological data derived from review of actual patient medical records, especially on the incidence and risk factors of IC in the general population. Most information is obtained from tertiary-care inpatient facilities or medical and pharmacy claims databases for which there may be a selection bias. Large database studies rely on the ascertainment of IC using diagnostic codes which are not specific to IC (see Supplementary Table 1), with limited or no medical record review, potentially leading to misclassification bias. A systematic review published in 2004 noted that the reported incidence of IC in the general population varied from 4.5 to 44 cases per 100,000 person-years, and concluded that the effect sizes of the most commonly reported risk factors were not adequately quantified in these population-based studies[8]. Since there has been no population-based study of patients with IC, we sought to estimate the incidence of IC in Olmsted County, Minnesota residents between 1976 and 2009, to describe the clinical features and natural history among unselected community patients, and to identify clinical variables that influence mortality in IC. We also performed a nested case-control study to assess the strength of association of putative risk factors with IC.

\section{Methods}

\section{Study Setting and Design}

Using the resources of the Rochester Epidemiology Project (REP)[9], we performed this population-based study in Olmsted County, Minnesota (population, 144,260 per 2010 US census) $[10,11]$. See Supplementary Material for further REP details. We developed a 
detailed protocol which included the hypothesis, definition of IC, risk factors, and all analytic procedures including sample size calculations prior to performing the study as recommended for high quality studies [12]. We followed the STROBE checklist for reporting our study[13].

Cases

Following written approval by the Institutional Review Boards of Mayo Clinic and Olmsted Medical Center, the REP data system was utilized to identify all county residents with a diagnosis of IC or vascular insufficiency of the intestine between January 1, 1976 and December 31, 2009. Coding systems utilized during this period included the Hospital Adaptation of the International Classification of Disease, second edition (HICDA-2), and International Classification of Disease, ninth edition (ICD-9). HICDA-2 codes for IC and vascular insufficiency of the intestine (5639-31 and 4442-xx) and the corresponding ICD-9 codes $(557,444.89)$ were used to identify potential cases. See Supplementary Material for case definitions.

\section{Controls}

Controls were randomly selected from the large pool of Olmsted County residents without IC who sought medical care at Mayo Medical Center or Olmsted Medical Center between January 1, 1976 and December 31, 2009. See Supplementary Material for additional details.

\section{Data Collection}

For cases, the medical records were reviewed for date of diagnosis of IC, method of diagnosis, subsite of bowel ischemia, dates of hospitalization, date(s) and type of surgery, and date of last follow-up or death. For both cases and controls, the records were reviewed for the presence of potential risk factors prior to the index date (date of diagnosis of IC for cases, and date of closest clinic visit for controls). A physician's diagnosis was used to define the risk factors (see Supplementary Material for definitions). Primary and secondary causes of death were recorded from death certificates. Study data were collected and managed using Research Electronic Data Capture (REDCap) hosted at Mayo Clinic[14].

\section{Statistical Analysis}

The incidence of IC was estimated by assuming that the entire Olmsted County population was at risk. Definite and probable cases of IC were included in the numerator, while personyears at risk based on decennial census numbers comprised the denominator. Potential risk factors for IC were evaluated using conditional logistic regression analysis, including year of birth as a covariate in the model. The odds ratios (OR) and 95\% CI are reported. Survival of the case cohort was estimated using the product-limit (Kaplan-Meier) method. Using just the IC patients (cases), the association of clinical variables with patient survival was estimated using multiple variable Cox proportional hazards regression. The data analysis was done in SAS version 9.2 (SAS Institute Inc., Cary, NC). The alpha-level (p value) for statistical significance was set at 0.05 . Additional details of the statistical analysis are provided in the Supplementary Material. 


\section{Results}

\section{Demographics and Clinical Features of Ischemic Colitis}

Between 1976 and 2009, 451 Olmsted County residents were first diagnosed with IC. Six patients (1.3\%) withheld research authorization. Out of the 445 patients, sixty-seven percent of the IC patients were females. The median age of diagnosis was 71.6 years (range 21.696.9) and 74\% were over the age of 60 years at the time of diagnosis of IC. Patients usually presented with abdominal pain (73\%), diarrhea (61\%), rectal bleeding (71\%) and abdominal tenderness $(60 \%)$. Various diagnostic methods were utilized to diagnose IC, such as endoscopy (73\%), surgery (16\%), autopsy (7\%) and radiology (4\%). The ischemic changes were distributed throughout the colon but most prevalent in the transverse (39\%), descending (56\%) and sigmoid (45\%) colon. Seventeen percent of patients underwent surgery, and in-hospital mortality was $11.5 \%$. Table 1 provides the demographics and clinical features of the 445 IC cases in more detail.

\section{Incidence}

The overall age- and sex-adjusted incidence of IC during the study period was 16.3 per 100,000 person-years (95\% CI, 14.8 - 17.8) for definite and probable cases combined (12.6 per 100,000 [95\% CI, 11.3 - 14.0] for definite cases only). The incidence of IC varied a hundredfold by age (Figure 1A), with annual incidence rates ranging from 1.1 per 100,000 among those under age 40 years to 107 per 100,000 among those aged 80 years or older. The age- and sex-adjusted incidence rates of IC nearly quadrupled during the 34-year study period (Figure 1B), from 6.1 cases per 100,000 person-years (95\% CI, 3.2 - 9.1) in 1976 1980 to 22.9 per 100,000 (95\% CI, 18.6 - 27.3) in 2006 - 2009. For men, the age-adjusted rate increased two and half fold, while the adjusted rate rose more than five-fold among women (Figure 1B). See Supplementary Material for additional analyses.

\section{Risk Factor Analysis}

The prevalence of putative risk factors for IC among 445 cases and 890 controls is shown in Table 2. As expected, the odds for being a case were significantly higher in subjects with atherosclerotic diseases, with odds ratios (ORs, relative to those without atherosclerotic diseases) ranging between 2.6 for coronary disease and 7.9 for peripheral vascular disease. An episode of hypotension in the preceding month was strongly associated with the development of IC. Collagen vascular disease, congestive heart failure and COPD were also significantly associated with IC. In addition, the odds of developing IC were higher in cigarette smokers, both current and ever (relative to never smokers). A clinical history of IBS was not significantly associated with IC. The use of cardiovascular medications such as diuretics or digoxin and psychotropic medications within the past month was significantly associated with IC (Table 2). No case or control patient was on alosetron. See Supplementary Material for the risk factor analysis stratified by age groups, including Supplementary Tables 2, 3A, and 3B. 


\section{Outcomes}

The median follow-up among cases was 8.5 years (range, 1 day -27.7 years). Three hundred eighty-two cases were hospitalized ( $86 \%$ ), and the median length of hospitalization was 5.0 days (range, $0-234$ days). In 5 patients, the discharge date was not documented, and 44 patients died in-hospital. Surgery was required in 76 patients $(17 \%)$-see Supplementary Material for additional details. Among the 367 cases with follow-up for recurrence, a second episode of IC occurred in 25 patients. The cumulative risk of a recurrent episode of ischemic colitis was 3.3\% at 2 years (95\% CI, $1.4-5.3$ ) and $7.5 \%$ at 5 years (95\% CI, 4.4 - 10.6) (Supplementary Figure 2). In a univariate analysis, current and former smokers with COPD had higher likelihood of IC recurrence $(\mathrm{P}<0.01)$.

Two hundred forty patients died during the period of observation (20 patients [4\%] were diagnosed at autopsy). Thirty-two out of 239 deaths (13.7\%) had IC as a primary or secondary cause of death. See Supplementary Material for other causes of death. Overall survival was worse than in the Olmsted County non-IC controls ( $p<0.0001$, log-rank) (Figure 2), and patients with right-sided colon involvement had even lower survival (Supplementary Figure 3). Inpatient mortality in IC cases was 11.5\%. The 30-, 60-, and 90day survival in IC cases was $85 \%, 84 \%$, and $82 \%$, respectively, compared to $30-, 60-$, and 90-day survival in the matched controls of $99.9 \%$ at all 3 timepoints. The overall survival at 1 and 5 years after diagnosis was $75 \%$ and $59 \%$, respectively, in IC cases as compared to $99 \%$ and $90 \%$, respectively, in controls. Figure 3 provides further details of survival among cases and controls in the different age groups. Using a multiple variable model, we identified the following risk factors for mortality, including age $\geq 40$ years, male gender, right-sided colonic involvement, concomitant small bowel involvement and COPD (Table $3)$.

\section{Discussion}

In this population-based study of unselected community patients, the overall annual incidence of IC between 1976 and 2009 was 16 cases per 100,000 person-years. There was a hundredfold difference in incidence between county residents younger than 40 years and those age 80 years or older. The age-and sex-adjusted incidence of IC nearly quadrupled over the course of 34 years, from 6.1 cases per 100,000 person-years in 1976-1980 to 22.9 per 100,000 person-years in 2005-2009. Previous reports of the incidence of ischemic colitis are inconsistent, varying between 4.5 and 44 cases per 100,000 person-years[15-20]. Most of these studies used ICD-9 codes to identify cases, with limited or no review of patient medical records for validation of case finding, potentially resulting in misclassification bias. We believe that our study, which involves a community-wide medical records linkage system with more complete case ascertainment by relying on histologic, clinical, radiographic, surgical and/or autopsy data for diagnosis, accounts for these differences, and provides a more realistic picture of the epidemiology of IC. In fact, we reviewed the medical records of 1147 patients with a potential diagnosis of IC based on ICD-9 codes to identify our 445 patients with IC (38.8\%) (see Supplementary Material). Thus, less than half the patients identified using diagnostic codes will be correctly classified. Furthermore, no study 
has estimated the incidence over three decades, with the longest study being only for a 7year period.

The rapid rise in incidence of IC over 34 years may have been due to a number of factors, including increasing life expectancy for patients with underlying predisposing chronic diseases, especially atherosclerotic diseases[21-25]. In addition, the 2010 U.S Census noted a steady increase in the proportion of U.S. adults over the age 65 years as compared to the entire U.S. population[26], which would be consistent with our finding of a significant rise in IC incidence in the older age-groups. Another potential explanation is misdiagnosis of ischemic colitis as colitis due to inflammatory bowel disease in the early part of the study period, and a decrease in this phenomenon as the diagnostic awareness of the condition increased. A 1981 review of 81 colitis cases presenting over the age of 50 years showed that up to $50 \%$ of patients with IC were initially diagnosed with inflammatory bowel disease[27]. In some case series of "indeterminate colitis," up to $10 \%$ of patients have ultimately been diagnosed with IC[28].

In Olmsted County, IC occurs most commonly among the elderly. Cardiovascular comorbidities such as hypertension, coronary artery disease, peripheral and cerebral vascular disease, congestive heart failure and cigarette smoking were common. Diuretics, digoxin, psychotropic and migraine medications occurred more frequently in the IC cases than controls. Only 62 cases (14\%) in our study were below 50 years of age, and this limited our ability to perform detailed analysis. However, these younger patients were less likely than older patients to have the "classic" cardiovascular risk factors, and more likely to be cigarette smokers and users of oral contraceptives. Middle-aged women with IC in our cohort were more likely than the older and younger groups to be on estrogen replacement. Our study cannot address the odds of developing IC in middle aged women on estrogen replacement therapy (ERT), but does highlight the increase in incidence and a reason to be cautious in starting ERT in middle age women who are smokers.

In our population, IBS was not a risk factor for IC. Previous studies have found that the incidence of IC was at least three time higher in IBS patients as compared to a matched control population[15-20]. With the exception of the report by Herve and colleagues[19], these studies used ICD-9 codes, with limited or no review of patient medical records for validation of case finding, potentially resulting in misclassification bias as highlighted above. On the other hand, the study by Herve et al included only hospitalized IC patients, and noted a lower prevalence of $1.6 \%$ of IBS in controls, compared to an expected rate of $4.7 \%$ in the general French population as reported by the authors, and may be indicative of inadequate matching[19]. Our study did show a higher odds for IC in subjects with atherosclerotic diseases as highlighted in hospital-based manual record review studies [2,3]. In addition, our rate of surgery (17\%) was comparable to those of Brandt et al[2] (19.8\%) and Sotiriadis et al[29] (22.3\%), thus highlighting the need to review records in any study of IC.

A recent study on the burden of gastrointestinal (GI) diseases identified aspiration pneumonia (Pneumonitis due to inhalation of food or vomitus [ICD 507]) as the number one nonmalignant GI cause for in-hospital mortality followed by viral hepatitis at $6.9 \%$ [30]. This 
would make IC the number two cause for in hospital mortality (11.5\%) among nonmalignant GI disorders, a significant burden which is generally unrecognized by physicians. The fiveyear survival among IC cases was 58\% as compared to $90 \%$ in the Olmsted County controls. Age older than 50 years, right-sided colonic involvement, small bowel involvement, COPD and male gender were all independent predictors of mortality. This is similar to referral center-based studies by Sotiriadis et al[[29] and Brandt et al[2] which found right-sided colonic involvement to be associated with higher mortality. Given the high in-hospital mortality with IC, older male patients with COPD need closer observation.

Our study also highlights that IC predominantly affects people over 60 years, and with the increase in proportion of older population in United States[26], we would expect to see the incidence of IC rise even further in the coming decades. The management of IC is mainly supportive, with surgery reserved for patients with colonic infarction and necrosis. Thus, we need newer treatment modalities for a disease with limited therapeutic options and an expected rise in incidence.

Our study has several strengths. First, ascertainment of diagnosed cases approached $100 \%$ in this defined regional cohort. Most healthcare delivery systems in North America are not integrated, and population-based studies are difficult to perform. The REP utilizes a medical records linkage system that allows identification of all potential cases of IC recognized by healthcare providers in Olmsted County[10]. Secondly, this system provided complete access to the patients' complete (inpatient and outpatient) community medical records, which not only allowed validation of the diagnosis using strict, consistent criteria, but also provided a level of clinical detail not achievable with administrative data sets. Thirdly, we were able to select controls from the general population, review their medical records in similar fashion, and study the association between putative risk factors and diagnosis of IC. Finally, the natural history of a condition described in a population-based cohort such as this tends to be more accurate than that described among patients referred to a tertiary referral center[31].

Our study also had several limitations. Olmsted County is a small geographic region, and the results of our study may not be generalizable to the U.S. as a whole. In 1990, only $4 \%$ of Olmsted County residents were members of minority populations, increasing to $17 \%$ in 2010 but still lower than the rest of the U.S.[32]. More detailed analyses of subgroups, such as cases younger than 40 years, were limited for the same reason. We were also limited by the retrospective, chart-based nature of the study. For example, it is possible that over-thecounter medication use was not recorded in a comprehensive fashion.

In summary, the incidence of IC has increased over the last 34 years. IC in the community typically presents in older patients with multiple co-morbidities and is associated with high in-hospital mortality. Patients with COPD, age $>50$ years, males, right sided or small bowel involvement are at high risk of death and need closer monitoring and follow up.

\section{Supplementary Material}

Refer to Web version on PubMed Central for supplementary material. 


\section{Acknowledgments}

Supported in part by the Mayo Foundation for Medical Education \& Research, and made possible by the Rochester Epidemiology Project (Grant number R01 AG034676 from the National Institute on Aging).

Dr. Maneesh Dave was supported by an Inflammatory Bowel Disease Working Group research award. We wish to thank Debra A. Jewell, R.N. and Lawrence J. Timmons for their assistance in data abstraction.

Role of the Funding Sources: The funding sources, the National Institutes of Health, the Mayo Foundation for Medical Education and Research and the Inflammatory Bowel Disease Working Group, had no role in the design, conduct, or analysis of this study or in the decision to submit the manuscript for publication. GlaxoSmithKline had provided funding support for an earlier iteration of this cohort, and had no role in the decision to submit this manuscript for publication.

\section{References}

1. Brandt LJ, Boley SJ. American Gastrointestinal Association. AGA technical review on intestinal ischemia. Gastroenterology. 2000; 118:954-968. [PubMed: 10784596]

2. Brandt LJ, Feuerstadt P, Blaszka MC. Anatomic patterns, patient characteristics, and clinical outcomes in ischemic colitis: a study of 313 cases supported by histology. Am J Gastroenterol. 2010; 105:2245-2252. quiz 2253. [PubMed: 20531399]

3. Montoro MA, Brandt LJ, Santolaria S, et al. Clinical patterns and outcomes of ischaemic colitis: results of the Working Group for the Study of Ischaemic Colitis in Spain (CIE study). Scand J Gastroenterol. 2011; 46:236-246. [PubMed: 20961178]

4. Kimura T, Shinji A, Horiuchi A, et al. Clinical characteristics of young-onset ischemic colitis. Dig Dis Sci. 2012; 57:1652-1659. [PubMed: 22383082]

5. Preventza OA, Lazarides K, Sawyer MD. Ischemic colitis in young adults: a single-institution experience. J Gastrointest Surg. 2001; 5:388-392. [PubMed: 11985980]

6. Deana DG, Dean PJ. Reversible ischemic colitis in young women. Association with oral contraceptive use. Am J Surg Pathol. 1995; 19:454-462. [PubMed: 7694947]

7. Matsumoto T, Iida M, Kimura Y, Nanbu T, Fujishima M. Clinical features in young adult patients with ischaemic colitis. J Gastroenterol Hepatol. 1994; 9:572-575. [PubMed: 7865715]

8. Higgins PD, Davis KJ, Laine L. Systematic review: the epidemiology of ischaemic colitis. Aliment Pharmacol Ther. 2004; 19:729-738. [PubMed: 15043513]

9. Rocca WA, Yawn BP, St Sauver JL, Grossardt BR, Melton LJ 3rd. History of the Rochester Epidemiology Project: half a century of medical records linkage in a US population. Mayo Clin Proc. 2012; 87:1202-1213. [PubMed: 23199802]

10. St Sauver JL, Grossardt BR, Yawn BP, et al. Data resource profile: the Rochester Epidemiology Project (REP) medical records-linkage system. Int J Epidemiol. 2012; 41:1614-1624. [PubMed: 23159830]

11. St Sauver JL, Grossardt BR, Yawn BP, Melton LJ 3rd, Rocca WA. Use of a medical records linkage system to enumerate a dynamic population over time: the Rochester epidemiology project. Am J Epidemiol. 2011; 173:1059-1068. [PubMed: 21430193]

12. Thomas L, Peterson ED. The value of statistical analysis plans in observational research: defining high-quality research from the start. Jama. 2012; 308:773-774. [PubMed: 22910753]

13. von Elm E, Altman DG, Egger M, et al. The Strengthening the Reporting of Observational Studies in Epidemiology (STROBE) statement: guidelines for reporting observational studies. Ann Intern Med. 2007; 147:573-577. [PubMed: 17938396]

14. Harris PA, Taylor R, Thielke R, et al. Research electronic data capture (REDCap)--a metadatadriven methodology and workflow process for providing translational research informatics support. J Biomed Inform. 2009; 42:377-381. [PubMed: 18929686]

15. Cole JA, Cook SF, Sands BE, et al. Occurrence of colon ischemia in relation to irritable bowel syndrome. Am J Gastroenterol. 2004; 99:486-491. [PubMed: 15056090]

16. Chang L, Kahler KH, Sarawate C, Quimbo R, Kralstein J. Assessment of potential risk factors associated with ischaemic colitis. Neurogastroenterol Motil. 2008; 20:36-42. [PubMed: 17919313] 
17. Suh DC, Kahler KH, Choi IS, et al. Patients with irritable bowel syndrome or constipation have an increased risk for ischaemic colitis. Aliment Pharmacol Ther. 2007; 25:681-692. [PubMed: 17311601]

18. Walker AM, Bohn RL, Cali C, et al. Risk factors for colon ischemia. Am J Gastroenterol. 2004; 99:1333-1337. [PubMed: 15233674]

19. Herve S, Beaugerie L, Bouhnik Y, et al. Irritable bowel syndrome is more frequent in patients hospitalized for ischaemic colitis: results of a case-control study. Neurogastroenterol Motil. 2009; 21:1170-e1102. [PubMed: 19460104]

20. Huerta C, Rivero E, Montoro MA, Garcia-Rodriguez LA. Risk factors for intestinal ischaemia among patients registered in a UK primary care database: a nested case-control study. Aliment Pharmacol Ther. 2011; 33:969-978. [PubMed: 21366637]

21. Burke GL, Sprafka JM, Folsom AR, et al. Trends in CHD mortality, morbidity and risk factor levels from 1960 to 1986: the Minnesota Heart Survey. Int J Epidemiol. 1989; 18:S73-81. [PubMed: 2807710]

22. Ergin A, Muntner P, Sherwin R, He J. Secular trends in cardiovascular disease mortality, incidence, and case fatality rates in adults in the United States. Am J Med. 2004; 117:219-227. [PubMed: 15308430]

23. Fowkes FG, Rudan D, Rudan I, et al. Comparison of global estimates of prevalence and risk factors for peripheral artery disease in 2000 and 2010: a systematic review and analysis. Lancet. 2013; 382:1329-1340. [PubMed: 23915883]

24. McGovern PG, Jacobs DR Jr, Shahar E, et al. Trends in acute coronary heart disease mortality, morbidity, and medical care from 1985 through 1997: the Minnesota heart survey. Circulation. 2001; 104:19-24. [PubMed: 11435332]

25. Lee JW, Brancati FL, Yeh HC. Trends in the prevalence of type 2 diabetes in Asians versus whites: results from the United States National Health Interview Survey, 1997-2008. Diabetes Care. 2011; 34:353-357. [PubMed: 21216863]

26. Werner CA. The Older Population: 2010 Census Briefs. Nov.2011 C2010BR-09.

27. Brandt L, Boley S, Goldberg L, Mitsudo S, Berman A. Colitis in the elderly. A reappraisal. Am J Gastroenterol. 1981; 76:239-245. [PubMed: 7315820]

28. Miniello S, Testini M, Piccinni G, et al. The uncertain primary diagnosis of inflammatory bowel diseases. Panminerva Med. 2002; 44:233-236. [PubMed: 12094138]

29. Sotiriadis J, Brandt LJ, Behin DS, Southern WN. Ischemic colitis has a worse prognosis when isolated to the right side of the colon. Am J Gastroenterol. 2007; 102:2247-2252. [PubMed: 17561968]

30. Peery AF, Dellon ES, Lund J, et al. Burden of gastrointestinal disease in the United States: 2012 update. Gastroenterology. 2012; 143:1179-1187. e1171-1173. [PubMed: 22885331]

31. Melton LJ 3rd. Selection bias in the referral of patients and the natural history of surgical conditions. Mayo Clin Proc. 1985; 60:880-885. [PubMed: 4068763]

32. St Sauver JL, Grossardt BR, Leibson CL, et al. Generalizability of epidemiological findings and public health decisions: an illustration from the Rochester Epidemiology Project. Mayo Clin Proc. 2012; 87:151-160. [PubMed: 22305027] 
A.

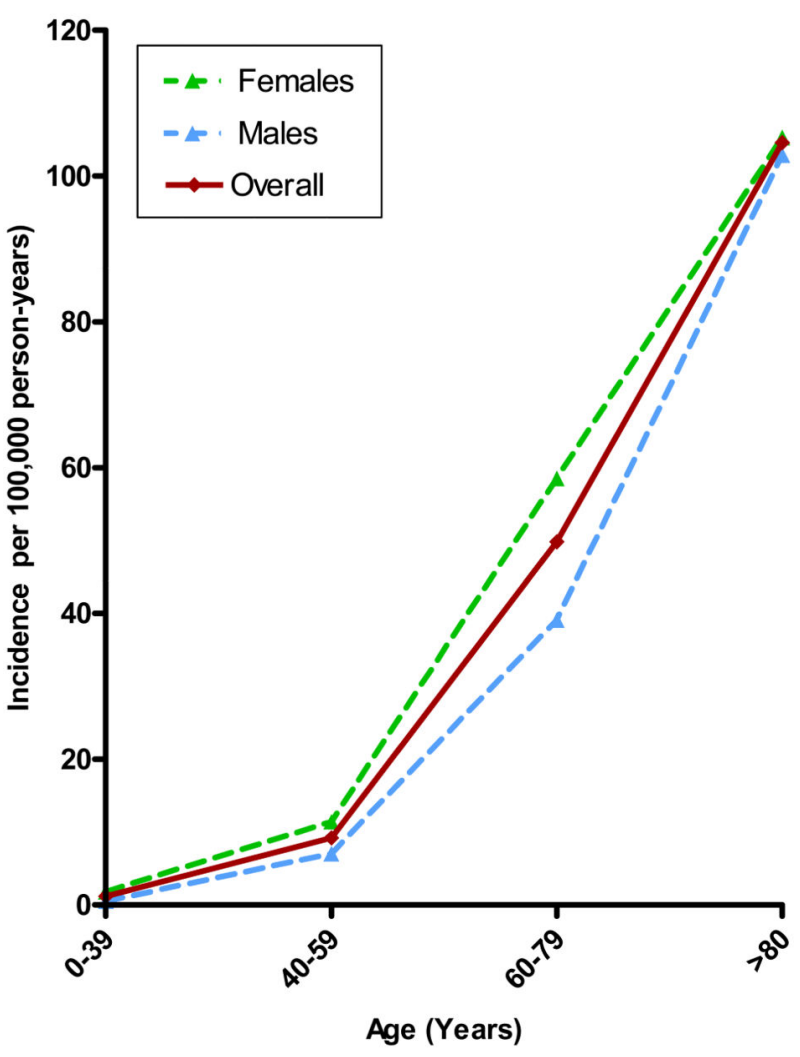


B.

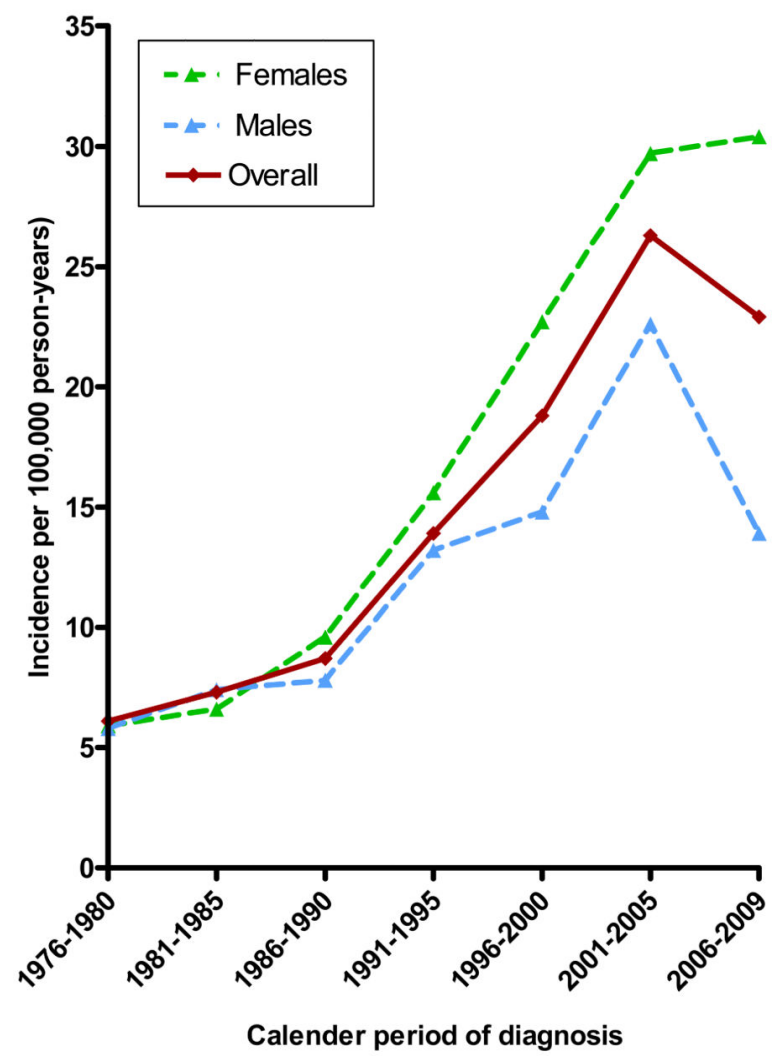

Figure 1.

A. Age-specific incidence of ischemic colitis in males, females and together in both sexes among Olmsted County, Minnesota, residents 1976-09. B. Age-adjusted incidence rate of ischemic colitis in males, females and together in both sexes among Olmsted County, Minnesota, residents 1976-2009. 


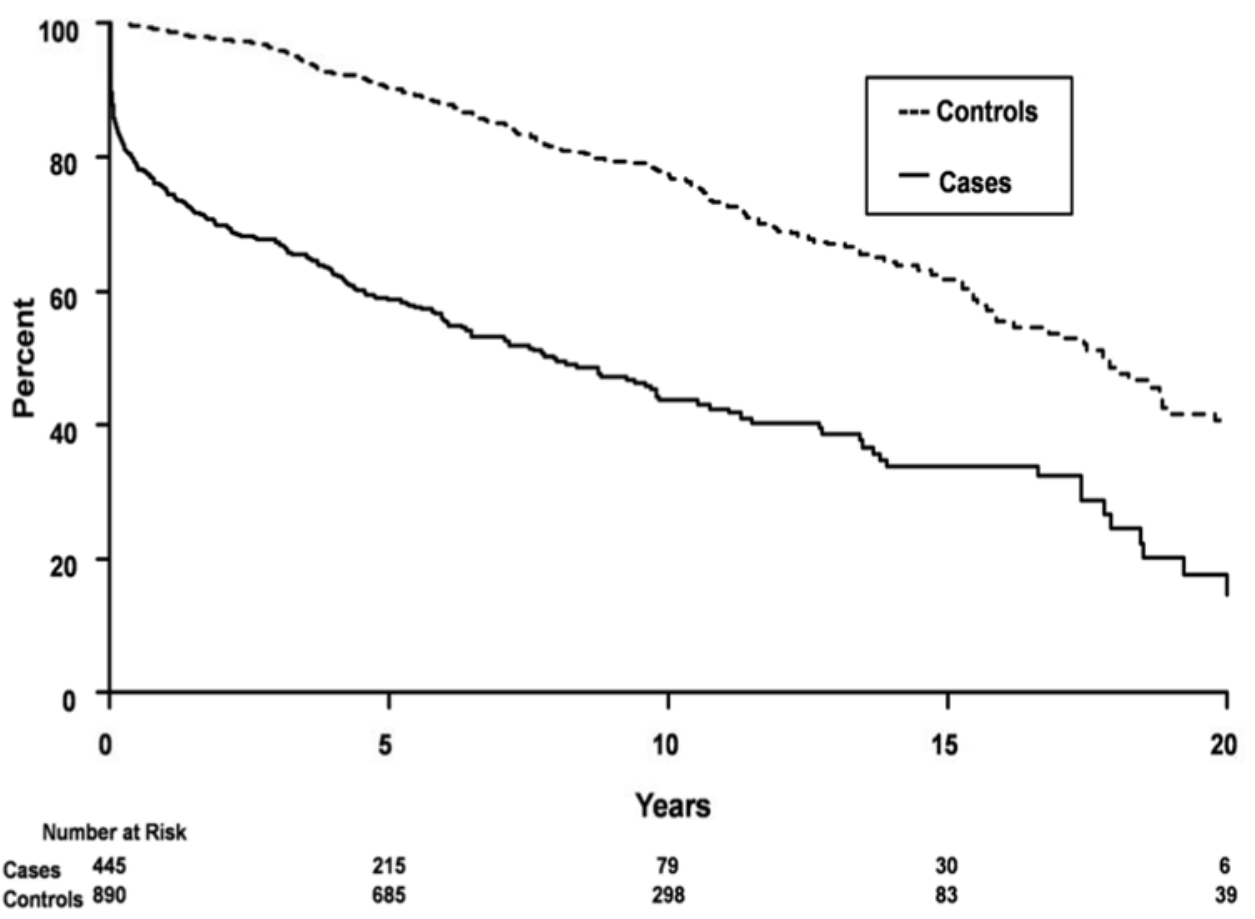

Figure 2.

Overall survival of cases with ischemic colitis from the time of diagnosis in Olmsted County, Minnesota, 1976-2009 along their matched controls from time of index date. 

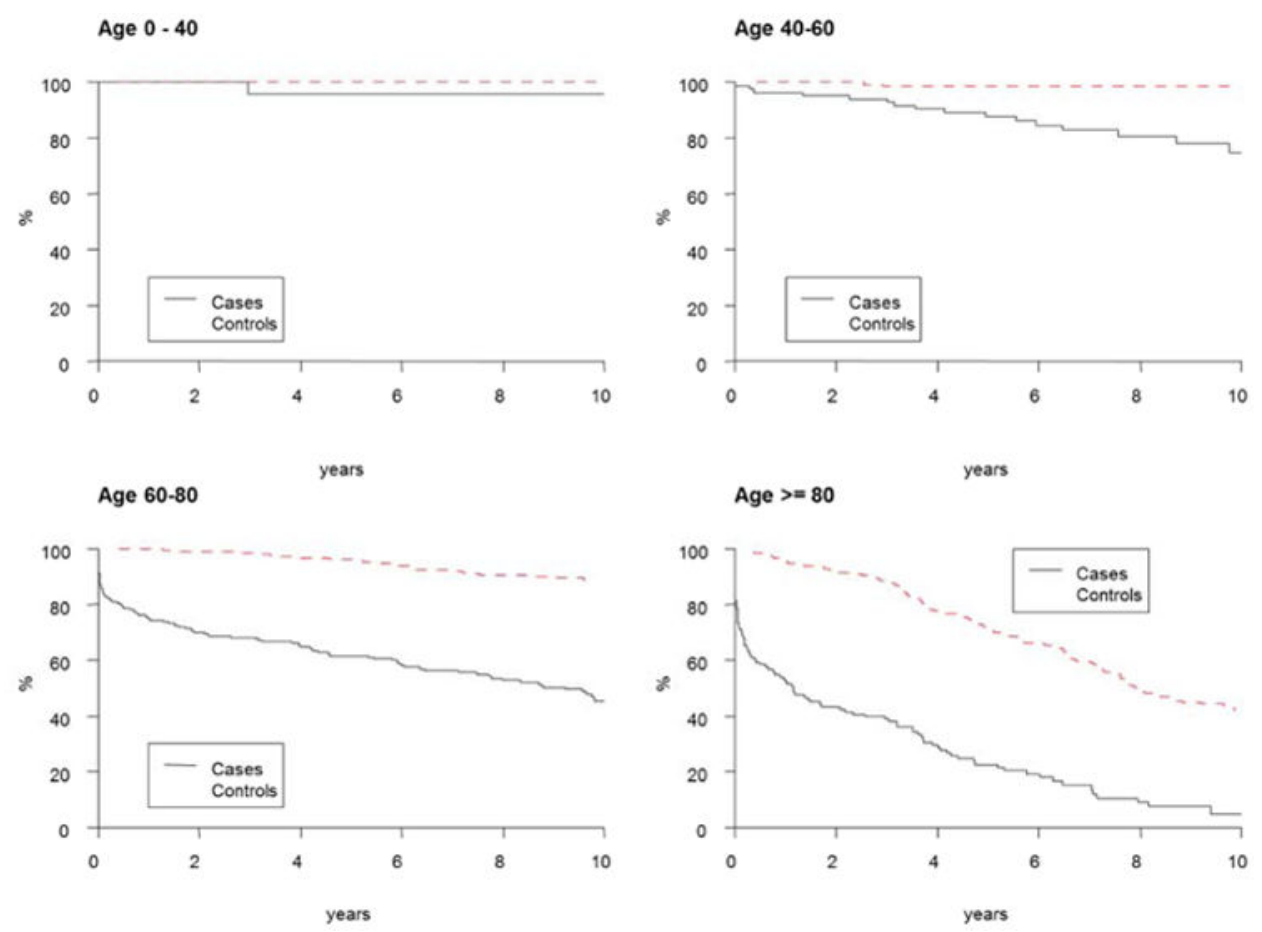

Figure 3.

Overall survival of cases with ischemic colitis from time of diagnosis and matched controls from index date in Olmsted County, Minnesota, 1976-2009 stratified by age groups: 3A, $<40$ years; 3B, $40-59$ years; 3 C, $60-79$ years; and $3 D$, 280 years. 


\section{Table 1}

Demographics and clinical features of the 445 Olmsted County, Minnesota residents diagnosed with ischemic colitis between 1976 and 2009.

\begin{tabular}{|c|c|}
\hline & $\mathbf{N}(\%)$ \\
\hline Total & 445 \\
\hline Female & $297(67 \%)$ \\
\hline \multicolumn{2}{|l|}{ Diagnostic category } \\
\hline Definite & $346(78 \%)$ \\
\hline Probable & $99(22 \%)$ \\
\hline Median age of diagnosis, years (range) & $71.6(21.6-96.9)$ \\
\hline \multicolumn{2}{|l|}{ Age of diagnosis } \\
\hline$<40$ years & $27(6 \%)$ \\
\hline $40-60$ years & $89(20 \%)$ \\
\hline $60-80$ years & $215(48 \%)$ \\
\hline$>80$ years & $114(26 \%)$ \\
\hline \multicolumn{2}{|l|}{ Presenting symptoms } \\
\hline Abdominal pain & $326(73 \%)$ \\
\hline Diarrhea (increased freq./loose stool) & $270(61 \%)$ \\
\hline Rectal bleed & $316(71 \%)$ \\
\hline \multicolumn{2}{|l|}{ Presenting signs } \\
\hline Abdominal tenderness & $267(60 \%)$ \\
\hline Rebound tenderness/guarding & $52(12 \%)$ \\
\hline Temp. $>38$ degree Celsius & $40(9 \%)$ \\
\hline Body mass index $>30$ & $89 / 348(26 \%)$ \\
\hline \multicolumn{2}{|l|}{ Method of diagnosis } \\
\hline Endoscopy & $323(73 \%)$ \\
\hline Radiology & $32(7 \%)$ \\
\hline Surgery & $70(16 \%)$ \\
\hline Autopsy & $20(4 \%)$ \\
\hline \multicolumn{2}{|l|}{ Ischemic change distribution } \\
\hline Cecum/ascending colon & $106(24 \%)$ \\
\hline Transverse & $172(39 \%)$ \\
\hline Descending & $248(56 \%)$ \\
\hline Sigmoid & $201(45 \%)$ \\
\hline Rectum & $66(15 \%)$ \\
\hline Small bowel & $37(8 \%)$ \\
\hline Low hemoglobin concentration $(<12 \mathrm{~g} / \mathrm{dl}$ in females and $<13.5 \mathrm{~g} / \mathrm{dl}$ in males $)$ & $154 / 423(36 \%)$ \\
\hline \multicolumn{2}{|l|}{ Type of surgery } \\
\hline Segmental sigmoid colectomy & $5(1 \%)$ \\
\hline Subtotal colectomy & $32(7 \%)$ \\
\hline
\end{tabular}

Clin Gastroenterol Hepatol. Author manuscript; available in PMC 2016 April 01. 


\begin{tabular}{|l|c|}
\hline & $\mathbf{N}(\boldsymbol{\%})$ \\
\hline Proctocolectomy & $3(1 \%)$ \\
\hline Abdominal exploration & $26(6 \%)$ \\
\hline Others & $10(2 \%)$ \\
\hline End ileostomy or colostomy & $30(7 \%)$ \\
\hline Median length of stay, days (range) & $5(1-234)$ \\
\hline Mortality during hospital admission & $44 / 382(11.5 \%)$ \\
\hline Median follow-up, years (range) & $8.5(1$ day -27.7 years) \\
\hline
\end{tabular}




\section{Table 2}

Relative risks (odds ratios) of putative risk factors for ischemic colitis among 445 Olmsted County, Minnesota residents diagnosed with ischemic colitis between 1976 and 2009 (cases) and 890 residents without ischemic colitis (controls).

\begin{tabular}{|c|c|c|c|}
\hline Co-Morbidities & $\begin{array}{c}\text { Overall Prevalence in Cases, } \\
n(\%)\end{array}$ & $\begin{array}{l}\text { Overall Prevalence in } \\
\text { Controls, } \mathbf{n}(\%)\end{array}$ & Odds Ratio (95\% CI) * \\
\hline Hypertension & $266(60)$ & $390(44)$ & $2.1(1.6,2.7)$ \\
\hline Coronary artery disease & $138(31)$ & $141(16)$ & $2.6(2.0,3.5)$ \\
\hline Peripheral vascular disease & $85(19)$ & $38(4)$ & $7.9(4.7,13.2)$ \\
\hline Cerebrovascular disease & $91(20)$ & $70(8)$ & $3.2(2.3,4.6)$ \\
\hline Hypotensive episode past month & $82(18)$ & $5(1)$ & $33.0(13.3,80.9)$ \\
\hline Congestive heart failure & $70(16)$ & $43(5)$ & $4.1(2.6,6.3)$ \\
\hline Hyperlipidemia & $146(33)$ & $358(40)$ & $0.7(0.5,0.9)$ \\
\hline Current smoking & $79(18)$ & $94(11)$ & $1.9(1.3,2.7)$ \\
\hline Ever smoking (current plus former) & $240(55)$ & $412(47)$ & $1.4(1.1,1.8)$ \\
\hline Diabetes mellitus & $77(17)$ & $90(10)$ & $2.0(1.4,2.8)$ \\
\hline Irritable bowel syndrome & $33(7)$ & $49(6)$ & $1.4(0.9,2.3)$ \\
\hline History of thromboembolism & $29(6)$ & $31(3)$ & $1.9(1.2,3.3)$ \\
\hline Aortic aneurysm or coronary bypass surgery & $33(7)$ & $29(3)$ & $2.5(1.5,4.2)$ \\
\hline Collagen vascular disease & $12(3)$ & $3(0.3)$ & $8.0(2.2,28.3)$ \\
\hline Chronic obstructive pulmonary disease & $67(15)$ & $30(5)$ & $3.1(1.8,5.2)$ \\
\hline Obesity (BMI >30) & $89(26)$ & $242(28)$ & $0.9(0.6,1.3)$ \\
\hline \multicolumn{4}{|l|}{ Medication Use (Past 30 Days) } \\
\hline Diuretics & $160(36)$ & $235(26)$ & $1.6(1.2,2.1)$ \\
\hline Digoxin & $40(9)$ & $26(3)$ & $3.6(2.1,6.2)$ \\
\hline NSAIDs & $68(15)$ & $154(17)$ & $0.9(0.6,1.2)$ \\
\hline Estrogen replacement ${ }^{\dagger}$ & $46(15)$ & $90(15)$ & $1.0(0.7,1.5)$ \\
\hline Psychotropic medications & $10(2)$ & $6(1)$ & $3.7(1.3,11.0)$ \\
\hline Oral contraceptives ${ }^{\dagger}$ & $9(3)$ & $25(4)$ & $0.7(0.3,1.5)$ \\
\hline Pseudoephedrine & $4(1)$ & $7(1)$ & $1.1(0.3,3.9)$ \\
\hline Migraine medications & $7(2)$ & $6(0.7)$ & $2.3(0.8,6.9)$ \\
\hline Gold & 0 & 0 & - \\
\hline
\end{tabular}

* Odds ratio and 95\% confidence interval using conditional logistic regression (which accounts for the matching) including only birth date as a covariate. ${ }^{\dagger}$ Among the 297 female ischemic colitis patients and their corresponding controls ( 6 males did receive estrogen therapy[2 ischemic colitis patients
and 4 controls] but are not included in the analysis). 
Table 3

Predictors of mortality among 445 IC cases from Olmsted County, Minnesota calculated using univariate proportional hazards regression and multiple Cox proportional hazards regression analyses.

\begin{tabular}{|c|c|c|c|c|}
\hline \multirow[t]{2}{*}{ Risk factors } & \multicolumn{2}{|c|}{ Univariate proportional hazards regression model } & \multicolumn{2}{|c|}{ Multiple Cox proportional hazards regression model } \\
\hline & Hazard Ratio (95\% CI) & $P$ - value & Hazard Ratio (95\% CI) & $P$ - value \\
\hline \multicolumn{5}{|l|}{ Disease Extent } \\
\hline Cecum/ascending & $1.9(1.5-2.56)$ & $<0.001$ & $1.6(1.2-2.2)$ & 0.003 \\
\hline Other & 1.0 (reference) & & 1.0 (reference) & \\
\hline \multicolumn{5}{|l|}{ Gender } \\
\hline Male & $1.4(1.1-1.8)$ & 0.022 & $1.4(1.05-1.8)$ & 0.02 \\
\hline Female & 1.0 (reference) & & 1.0 (reference) & \\
\hline \multicolumn{5}{|l|}{ Age (years) } \\
\hline 40 to 59 & $3.5(0.8-14.9)$ & $<0.001$ & $5.8(1.3-25.2)$ & $<0.001$ \\
\hline 60 to 79 & $9.9(2.4-40.0)$ & & $17.6(4.2-74.9)$ & \\
\hline$\geq 80$ & $30.4(7.4-123.8)$ & & $58.3(13.6-250.9)$ & \\
\hline$<40$ & 1.0 (reference) & & 1.0 (reference) & \\
\hline \multicolumn{5}{|c|}{ Small bowel involvement } \\
\hline Yes & $3.7(2.5-5.5)$ & $<0.001$ & $3.2(2.0-5.2)$ & $<0.001$ \\
\hline No & 1.0 (reference) & & 1.0 (reference) & \\
\hline \multicolumn{5}{|l|}{ COPD } \\
\hline Yes & $2.8(2.1-3.7)$ & $<0.001$ & $2.1(1.5-2.9)$ & $<0.001$ \\
\hline No & 1.0 (reference) & & 1.0 (reference) & \\
\hline
\end{tabular}

